\title{
On the Severity of Carpal Tunnel Syndrome: Metabolic Syndrome or Obesity
}

\author{
Angelo V. Vasiliadis ${ }^{1,2,3 *}$, George Charitoudis ${ }^{1}$, Theofanis Kantas ${ }^{3}$, Cristos Kalitsis ${ }^{3}$, George Giovanidis ${ }^{4}$, George Biniaris ${ }^{3}$ \\ ${ }^{1}$ Department of Orthopaedic Surgery, General Hospital of Thessaloniki "Papageorgiou", Eukarpia, Thessaloniki, Greece; \\ ${ }^{2}$ School of Medicine, Aristotle University of Thessaloniki, Thessaloniki, Greece; ${ }^{3}$ Department of Orthopaedic Surgery, General \\ Hospital of Katerini, Katerini, Greece; ${ }^{4}$ Department of Orthopaedic Surgery, General Hospital of Chalkida, Chalkida, Greece
}

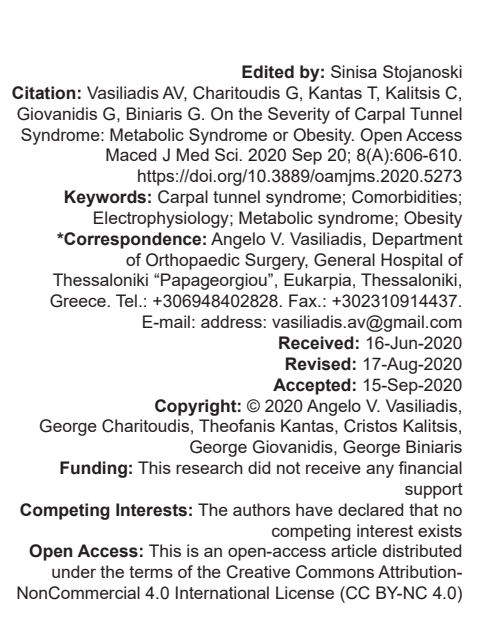

\section{Abstract}

AIM: This study aimed to determine the relationship between CTS, metabolic syndrome and obesity and to compare the severity of CTS between patients with or without metabolic syndrome (MS) and patients with or without obesity.

METHODS: In this prospective study, patients with clinical and electrophysiological confirmed diagnosis of CTS were included. The waist circumference, blood pressure, fasting blood glucose, fasting triglycerides and high/low density lipoprotein cholesterol levels were recorded. Patients were categorized having metabolic syndrome according to Adult Treatment Panel III definition, while body mass index was used to identify obesity.

RESULTS: A total of 65 patients with a mean age of $58.91 \pm 12.49$ years were included. MS was found in $39(60 \%)$ patients and obesity in $27(41.5 \%)$ patients. The CTS was described as mild, moderate and severe in 8,12 and 19 hands of those with MS and in 2, 6, and 18 of those without MS respectively ( $p=0.207$ ). There were no statistically significant results observed between BMI and the severity of CTS $(p>0.05)$. The mean waist circumference was $94.75 \pm 7.36,98.78 \pm 9.64,106.42 \pm 10.78,86.41 \pm 6.77$ for patients with $\mathrm{MS}^{+} \mathrm{O}^{-}, \mathrm{MS}^{-} \mathrm{O}^{+}, \mathrm{MS}^{+} \mathrm{O}^{+}$and $\mathrm{MS}^{-} \mathrm{O}^{-}$ respectively $(p<0.002)$.

CONCLUSION: CTS appears to be more severe in patients with MS than in patients with obesity. Central obesity is one of the well-known risk factors for CTS, but components of MS may have a greater effect on the severity of CTS

\section{Background}

Carpal tunnel syndrome (CTS) is the most common upper limb entrapment neuropathy, which ranges from $2.7 \%$ to $5.8 \%$ in the general population [1]. CTS is more common in women with a male-to-female ratio between 1:3.1 and 1:10.1 [2]. Although its exact cause and pathogenesis are unclear, it is commonly associated with several conditions, such as obesity, hypothyroidism, diabetes mellitus, amyloidosis, and pregnancy [3], [4]. The metabolic syndrome (MS) is referred to the cooccurrence of several known cardiovascular risk factors, including insulin resistance, central obesity, atherogenic dyslipidemia, and hypertension [3]. The first definition attempt was made in 1999 by the World Health Organization (WHO), which proposed that MS may be defined by the presence of insulin resistance or its surrogates. In 2001, the National Cholesterol Education Program Adult Treatment Panel III (NCEP:ATPIII) published a new set of criteria that included waist circumference, blood lipids, blood pressure, and fasting glucose [5].
The previous epidemiological studies have shown that constitutional (obesity and smoking), hormonal, and musculoskeletal risk factors are associated with CTS and recent research indicated that MS plays an important role in CTS [3], [4].

The aim of the present study was to determine the relationship between CTS, MS, and obesity (body mass index $[\mathrm{BMI}] \geq 30 \mathrm{~kg} / \mathrm{m}^{2}$ ). Furthermore, the severity of CTS was compared between patients with or without central obesity and patients with or without MS.

\section{Methods}

\section{Participants and data collection}

All patients $(n=65)$ diagnosed with CTS at the Department of Orthopaedic Surgery in the General Hospital of Katerini from January 2019 to December 2019 were included in the study. They were referred to the electrophysiology laboratory with sensory or motor 
complaints in the upper limbs. The variables recorded were age, gender, height, weight, BMI, additional comorbidities (diabetes mellitus, hypertension, hypothyroidism, dyslipidemia, cardiovascular disease, nephropathy, etc.), and upper extremities trauma history were documented. Patients who previously received corticosteroid or hormone replacement treatments, had a history of rheumatoid arthritis or wrist fracture were excluded from the study. Patients conforming to polyneuropathy, cervical radiculopathy, and thoracic outlet syndrome as a result of EMG were also excluded from the study. The protocol was reviewed and approved by the Scientific Committee of the General Hospital of Katerini. All participants had signed the written informed consent.

Patients were divided into two groups according to the presence or the absence of MS. According to the NCEP ATP III definition, MS is present if three or more of the following five criteria are met: Waist circumference over $102 \mathrm{~cm}$ (males) or $88 \mathrm{~cm}$ (females), blood pressure over 130/85 mmHg (or taking anti-hypertension medication), fasting triglyceride (TG) level over $150 \mathrm{mg} / \mathrm{dL}$, fasting high-density lipoprotein (HDL) cholesterol level less than $40 \mathrm{mg} / \mathrm{dL}$ (males) or $50 \mathrm{mg} / \mathrm{dL}$ (females), and fasting blood sugar over $100 \mathrm{mg} / \mathrm{dL}$ [5]. According to the WHO, obesity is a medical condition, which is defined as abnormal or excessive fat accumulation. BMI, which is calculated by dividing the body weight in kilograms by height in meters squared $\left(\mathrm{kg} / \mathrm{m}^{2}\right)$, was used to identify obesity. A person with a $\mathrm{BMI}$ of 30 or more is generally considered obese [6].

Nerveconductionstudiesandelectromyography were performed to resolve diagnostic uncertainty and to quantify and stratify disease severity. According to Padua's classification [7], patients were divided into five groups (Table 1). For statistical convenience and

Table 1: Neurophysiological classification of CTS

\begin{tabular}{ll}
\hline Grade & Neurophysiological findings \\
\hline Minimal CTS & "Standard negative" hands with abnormal comparative or \\
& segmental $(<7-8 \mathrm{~cm}$ ) tests \\
Mild CTS & Slowing of median digit-wrist segment and normal DML \\
Moderate CTS & Slowing of median digit-wrist segment and abnormal DML \\
Severe CTS & Absence of median SNAPS (digit-wrist segment) and abnormal \\
& DML \\
Extreme severe CTS & Absence of thenar motor (and sensory) response \\
\hline
\end{tabular}
DML: Distal motor latency, SNAPS: Sensory nerve action potentials.

significance, we modified this classification into three groups: (a) Minimal to mild CTS (Group I); (b) moderate CTS (Group II); and (c) severe to extremely severe CTS (Group III). The patients were divided into the following four groups according to the presence or absence of MS and/or obesity: (1) Metabolic syndrome only $\left(\mathrm{MS}^{+} \mathrm{O}^{-}\right)$, (2) obesity only $\left(\mathrm{MS}^{-} \mathrm{O}^{+}\right),(3)$ metabolic syndrome and obesity together $\left(\mathrm{MS}^{+} \mathrm{O}^{+}\right)$, and (4) neither metabolic syndrome nor obesity $\left(\mathrm{MS}^{-} \mathrm{O}^{-}\right)$. The demographic characteristics, the severity of CTS according to the electrophysiological findings of the subjects, were analyzed and compared among these four groups.

\section{Statistical analysis}

Collected data were analyzed with SPSS (Version 24.0). The Kolmogorov-Smirnov test was utilized for normality analysis. Student's t-test and Mann-Whitney U-test were utilized for the comparison of the quantities-continuous variables in our independent samples, for parametric and non-parametric distribution, respectively, in population divided into two categories. The one-way ANOVA test and the Kruskal-Wallis test were utilized for the comparison of the quantitiescontinuous variables in our independent samples, for parametric and non-parametric distribution, respectively, in population divided into more than 2 categories. Pearson- $\chi^{2}$ (cross-tabulation) was utilized for the comparison of the categorical variables. The level of significance was set at $p<0.05$.

\section{Results}

Among the 65 patients included in the study, $16(24.6 \%)$ were male and $49(75.4 \%)$ were female. The average age was $58.91 \pm 12.49$ years (56.75 \pm 12.28 for females and $65.5 \pm 11.03$ for males). Unilateral CTS was present in $30(46.2 \%)$ patients, while $35(53.8 \%)$ patients had bilateral CTS. Thirty-nine $(60 \%)$ of the patients were diagnosed with MS, while 26 $(40 \%)$ did not meet the diagnostic criteria. There was a statistically significant difference between patients with and without MS and age (62.03 \pm 11.57 years vs. 54.23 \pm 12.56 years, $p=0.013$ ), while there was no difference between the two genders (females/males: $30 / 9$ vs. 19/7, $\mathrm{p}=0.724)$. Bilateral CTS was present in $22(56.4 \%)$ of the 39 patients with MS and in $13(50 \%)$ of the 26 patients without MS $(p=0.612)$. The CTS was described as mild, moderate, and severe in 8,12 , and 19 hands of those with MS and in 2, 6, and 18 of those without MS, respectively $(p=0.207)$ (Table 2$)$. The proportion of patients who had moderate and severe CTS was higher

Table 2: Age, gender, severity of CTS, and comorbidities in patients with or without MS

\begin{tabular}{|c|c|c|c|c|}
\hline Variables & All patients & $\begin{array}{l}\text { Patients with } \\
\text { MS }\end{array}$ & $\begin{array}{l}\text { Patients } \\
\text { without MS }\end{array}$ & $p$-value \\
\hline Age & $58.91 \pm 12.49$ & $62.02 \pm 11.57$ & $54.23 \pm 12.56$ & 0.013 \\
\hline Gender (F/M, n) & $16 / 49,65$ & $9 / 30,39$ & 7/19, 26 & 0.724 \\
\hline Bilateral CTS (n, \%) & $35(53.8 \%)$ & $22(56.4 \%)$ & $13(50 \%)$ & 0.612 \\
\hline \multicolumn{5}{|l|}{ Severity of CTS } \\
\hline Mild (n, \%) & $10(15.4 \%)$ & $8(20.5 \%)$ & $2(7.7 \%)$ & 0.207 \\
\hline Moderate (n, \%) & $18(27.7 \%)$ & $12(30.8 \%)$ & $6(23.1 \%)$ & \\
\hline Severe $(n, \%)$ & $37(56.9 \%)$ & $19(48.7 \%)$ & $18(69.2 \%)$ & \\
\hline \multicolumn{5}{|l|}{ Comorbidities } \\
\hline Hypertension (n, \%) & $34(52.3 \%)$ & $28(71.8 \%)$ & $6(23.1 \%)$ & $<0.001$ \\
\hline Dyslipidemia (n, \%) & $17(26.6 \%)$ & $17(43.6 \%)$ & & $<0.001$ \\
\hline Hypothyroidism (n, \%) & $10(15.4 \%)$ & $5(12.8 \%)$ & $5(19.2 \%)$ & 0.483 \\
\hline $\mathrm{DM}(\mathrm{n}, \%)$ & $7(10.8 \%)$ & $6(15.4 \%)$ & $1(3.8 \%)$ & 0.142 \\
\hline CVD (n, \%) & $7(10.8 \%)$ & $5(12.8 \%)$ & $2(7.7 \%)$ & 0.513 \\
\hline $\operatorname{GERD}(\mathrm{n}, \%)$ & $3(4.6 \%)$ & & $3(11.5 \%)$ & 0.030 \\
\hline $\mathrm{BPH}(\mathrm{n}, \%)$ & $1(1.5 \%)$ & $1(2.6 \%)$ & & 0.411 \\
\hline Anemia (n, \%) & $1(1.5 \%)$ & & $1(3.8 \%)$ & 0.217 \\
\hline Nephropathy (n, \%) & $1(1.5 \%)$ & & $1(3.8 \%)$ & 0.217 \\
\hline
\end{tabular}


in those with MS than in those without $(p=0.160)$. A majority $(69.2 \%)$ of patients, with or without MS, had at least one comorbidity, with hypertension being the most common 1 (52.3\%), followed by dyslipidemia (26.6\%), hypothyroidism (15.4\%), diabetes mellitus (10.8\%), and cardiovascular disease (10.8\%) (Table 2).

Based on the BMI, there were 7 patients $(10.8 \%)$ with normal weight (BMI: less than 25$), 31$ patients $(47.7 \%)$ were overweight (BMI: 25-29.9), and 27 patients (41.5\%) were obese (BMI: 30 and higher). In the first category, there was one patient with mild CTS, one patient with moderate CTS, and five patients with severe CTS. In the overweight category, there were 6 patients with mild CTS, 9 patients with moderate CTS, and 16 patients with severe CTS. In the patients with BMI of 30 and higher, there were 3 patients with mild CTS, 8 patients with moderate CTS, and 16 patients with severe CTS. There were no statistically significant difference observed between BMI and the severity of CTS $(p>0.05)$ (Figure 1).



Figure 1: Stratification of body mass index based on the severity of carpal tunnel syndrome

Stratification of the patients according to the presence/absence of MS/obesity yielded the following CTS patient distribution: $\mathrm{MS}^{+} \mathrm{O}^{-}, \mathrm{n}=4$; $\mathrm{MS}^{-} \mathrm{O}^{+}, \mathrm{n}=14$; $\mathrm{MS}^{+} \mathrm{O}^{+}, \mathrm{n}=35$; and $\mathrm{MS}^{-} \mathrm{O}^{-}, \mathrm{n}=12$. Comparison of the electrophysiological findings of these four patient groups revealed that the severity of CTS was worse in $\mathrm{MS}^{-} \mathrm{O}^{+}$patients than in $\mathrm{MS}^{+} \mathrm{O}^{-}$patients $(\mathrm{p}=0.369)$. The severity of CTS was worse in $\mathrm{MS}^{+} \mathrm{O}^{+}$patients than in $\mathrm{MS}^{+} \mathrm{O}^{-}, \mathrm{MS}^{-} \mathrm{O}^{+}$, and $\mathrm{MS}^{-} \mathrm{O}^{-}$patients $(\mathrm{p}=0.265)$. The electrophysiological findings in the four groups and the relationships between them are listed in Table 3.

Table 3: Severity of carpal tunnel syndrome according to the presence/absence of metabolic syndrome and/or obesity

\begin{tabular}{lllll}
\hline Group & Mild, $\mathrm{n}(\%)$ & Moderate, $\mathrm{n}(\%)$ & Severe, $\mathrm{n}(\%)$ & $\mathrm{p}$ value \\
\hline $\mathrm{MS}^{+} \mathrm{O}^{-}$ & $1(25)$ & $2(50)$ & $1(25)$ & 0.510 \\
$\mathrm{MS}^{-} \mathrm{O}^{+}$ & $2(14.3)$ & $3(21.4)$ & $9(64.3)$ & \\
$\mathrm{MS}^{+} \mathrm{O}^{+}$ & $7(20)$ & $10(28.6)$ & $18(51.4)$ & \\
$\mathrm{MS}^{-} \mathrm{O}^{-}$ & $0(0)$ & $3(25)$ & $9(75)$ & \\
\hline
\end{tabular}

${ }^{*}$ The threshold for statistical significance was $\mathrm{p}<0.05 . \mathrm{MS}^{+} \mathrm{O}^{-}$: CTS patients with metabolic syndrome only, $\mathrm{MS}^{-} \mathrm{O}^{+}$: CTS patients with obesity only, $\mathrm{MS}^{+} \mathrm{O}^{+}$: CTS patients with both metabolic syndrome and obesity, MS- ${ }^{-}$: CTS patients with neither metabolic syndrome nor obesity; MS: Metabolic syndrome, O: Obesity.

The occurrence of abdominal obesity, hypertension, hyperglycemia, and dyslipidemia (hypertriglyceridemia, high serum LDL, low serum HDL, and high serum cholesterol) was compared among the four groups (Table 4). The waist circumferences in the $\mathrm{MS}^{+} \mathrm{O}^{-}, \mathrm{MS}^{-} \mathrm{O}^{+}, \mathrm{MS}^{+} \mathrm{O}^{+}$, and $\mathrm{MS}^{-} \mathrm{O}^{-}$groups were 94.75 $\pm 7.36,98.79 \pm 9.64,106.42 \pm 10.78$, and $86.41 \pm 6.78$ $\mathrm{cm}$, respectively $(p<0.001)$ (Table 4$)$. The mean waist circumference of the $\mathrm{MS}^{+} \mathrm{O}^{-}$group was lower than in the $\mathrm{MS}^{-} \mathrm{O}^{+}$group $(\mathrm{p}=0.670)$ and $\mathrm{MS}^{+} \mathrm{O}^{+}$group $(\mathrm{p}=0.015)$. The frequencies of hypertension in the $\mathrm{MS}^{+} \mathrm{O}^{-}, \mathrm{MS}^{-} \mathrm{O}^{+}$, $\mathrm{MS}^{+} \mathrm{O}^{+}$, and $\mathrm{MS}^{-} \mathrm{O}^{-}$groups were $100 \%, 35.7 \%, 91.4 \%$, and $66.7 \%$, respectively ( $p=0.123$ ). The frequency of hypertension was lower in the $\mathrm{MS}^{-} \mathrm{O}^{+}$group than in the other three groups $(p<0.001)$. The frequencies of dyslipidemia in the $\mathrm{MS}^{+} \mathrm{O}^{-}$and $\mathrm{MS}^{+} \mathrm{O}^{+}$groups were $75 \%$ and $40 \%$, respectively ( $p=0.001)$. The frequencies of diabetes mellitus in the $\mathrm{MS}^{+} \mathrm{O}^{+}$and $\mathrm{MS}^{-} \mathrm{O}^{-}$groups were $17.1 \%$ and $8.3 \%$, respectively $(p<0.001)$.

\section{Discussion}

Carpal tunnel syndrome is the most common entrapment neuropathy with a prevalence of 2.7-5.8 in the general population [1], [8]. Clinical studies have shown that MS was found to be approximately 3 times more common in patients with CTS, while CTS was found to be more severe in patients with MS [9], [10]. A possible reason why CTS is more common in MS is that MS is a condition driven by inflammation with a variety of biomarkers and cell types are emerged as significant mediators of this inflammation. Mast cells in subcutaneous adipose tissue seem to play a crucial role

Table 4: Body mass index, presence of hypertension, dyslipidemia, hyperglycemia, and waist circumference in the carpal tunnel syndrome patients stratified according to the presence/absence of metabolic syndrome and/or obesity

\begin{tabular}{|c|c|c|c|c|c|}
\hline Variables & $\mathrm{MS}^{+} \mathrm{O}^{-}$ & $\mathrm{MS}^{-} \mathrm{O}^{+}$ & $\mathrm{MS}^{+} \mathrm{O}^{+}$ & $\mathrm{MS}^{-} \mathrm{O}^{-}$ & $p$-value ${ }^{*}$ \\
\hline $\mathrm{BMI}\left(\mathrm{kg} / \mathrm{m}^{2}\right)$ & $26.4 \pm 1.28$ & $29.17 \pm 2.7$ & $32.24 \pm 5.39$ & $24.92 \pm 2.78$ & $<0.001$ \\
\hline $\mathrm{SBP}(\mathrm{mmHg})$ & $148.75 \pm 17.42$ & $132.78 \pm 19.53$ & $145.42 \pm 15.5$ & $139.5 \pm 20.89$ & 0.123 \\
\hline $\mathrm{DBP}(\mathrm{mmHg})$ & $87.75 \pm 14.75$ & $82.28 \pm 12.07$ & $87.68 \pm 11.59$ & $87.66 \pm 10.78$ & 0.366 \\
\hline $\mathrm{TG}(\mathrm{mg} / \mathrm{dL})$ & $175.25 \pm 38.9$ & $106.64 \pm 40.53$ & $145.14 \pm 51.85$ & $93.08 \pm 25.6$ & 0.001 \\
\hline $\mathrm{HDL}(\mathrm{mg} / \mathrm{dL})$ & $42.15 \pm 6.51$ & $63.57 \pm 13.36$ & $56.05 \pm 19.5$ & $63.1 \pm 17.45$ & 0.017 \\
\hline LDL (mg/dL) & $125.3 \pm 36.52$ & $134.56 \pm 18.32$ & $110.47 \pm 31.85$ & $109.19 \pm 25.62$ & 0.045 \\
\hline Cholesterone (mg/dL) & $202.5 \pm 42.58$ & $219.42 \pm 26.34$ & $198.28 \pm 36.54$ & $190.75 \pm 37.34$ & 0.179 \\
\hline Glucose (mg/dL) & $129 \pm 14.25$ & $91.6 \pm 8.76$ & $123.57 \pm 45.11$ & $106.66 \pm 36.01$ & $<0.001$ \\
\hline Waist circumference $(\mathrm{cm})$ & $94.75 \pm 7.36$ & $98.78 \pm 9.64$ & $106.42 \pm 10.78$ & $86.41 \pm 6.77$ & $<0.001$ \\
\hline
\end{tabular}


in promotion both of inflammation and fibrosis around and within the median nerve resulting in the inhibition of nerve gliding [5], [9], [11].

The present study analyzed the impact of MS and obesity on the severity of CTS and evaluated the association between MS with or without obese people and CTS. The rate of MS in patients with CTS has been found to be between $48 \%$ and $75 \%$ in the previous studies [9], [10]. These reported different prevalence rates of MS in the patients with CTS may be the result of genetic factors, environmental/occupational conditions, the different age of the studied populations, and the lifestyle of the populations concerned. In agreement with these findings [9], [10], in the present study, MS was also found in $60 \%$ of patients with CTS with a mean age of $62.03 \pm 11.57$ years. CTS was also more severe in the patients with MS than in those without. Nowadays, MS is a major public health problem and is characterized by abdominal obesity, hypertension, dyslipidemia, and hyperglycemia [5].

Female patients and patients aged between 40 and 60 years are more likely to develop CTS. One study involved 107 patients with CTS (mean age $53.9 \pm$ 8.9), of whom $89.7 \%$ were female [10]. Yurdakul et al. included 200 patients with CTS (mean age 51.61 $\pm 11.86)$, of whom $140(70 \%)$ were female [9]. In a descriptive cross-sectional study of 112 patients with a mean age of $54 \pm 5$ years, $65 \%$ were female [11] Similar to these findings, $49(75.4 \%)$ of the patients in the present study were female.

Previously, Werner et al. reported that only $16 \%$ of individuals with a BMI below $20 \mathrm{~kg} / \mathrm{m}^{2}$ had CTS compared with $39 \%$ of individuals with BMI of $29 \mathrm{~kg} /$ $\mathrm{m}^{2}$ and higher [12]. They reported that CTS patients are 2 times more likely to be obese than slender ones and female patients are 2 times more likely to be obese. Nordstrom et al. demonstrated that a weight gain of about six pounds increased the risk of developing CTS by $8 \%$ [13]. This trend was also observed in the patients of the present study, while $42.5 \%$ of the patients had a BMl of $\geq 30 \mathrm{~kg} / \mathrm{m}^{2}$. Female patients were also 3 times more likely to be obese than male patients. We also identified a relationship between severity of CTS and obese population, with the highest BMI in patients with severe CTS. In another study by Kouyoumdjian et al., they studied the influence of higher BMI in the severity of CTS and found that CTS had a significant correlation with higher BMI when compared to control subjects [14].

Hyperglycemia, obesity, and dyslipidemia, which are the components of MS, have been proposed as possible risk factors for CTS [3]. In the present study, comparisons between patients with or without MS and obesity revealed significantly higher waist circumference in patients with $\mathrm{MS}^{+} \mathrm{O}^{+}$. Moreover, lipid profile including HDL and serum TG was significantly different in those with $\mathrm{MS}^{+} \mathrm{O}^{-}$compared to those with $\mathrm{MS}^{-} \mathrm{O}^{+}$. Hyperglycemia was significantly higher in patients with $\mathrm{MS}^{+} \mathrm{O}^{-}$compared to $\mathrm{MS}^{-} \mathrm{O}^{+}$patients. El Gharieb et al. recruited 103 female patients of CTS with a mean age between 31 and 42 years (according to the severity of CTS) and found mean triglycerides levels $159.02 \pm$ $53.7 \mathrm{mg} / \mathrm{dL}$, mean LDL cholesterol levels $140.45 \pm$ $47.74 \mathrm{mg} / \mathrm{dL}$, and mean HDL cholesterol levels $54.34 \pm$ $8.62 \mathrm{mg} / \mathrm{dL}$ [15]. In the present study, the patients' mean triglycerides levels were elevated $175.25 \pm 38.9 \mathrm{mg} / \mathrm{dL}$ and their mean LDL/HDL cholesterol levels were lower $125.3 \pm 36.52 / 56.05 \pm 19.5 \mathrm{mg} / \mathrm{dL}$. These differences could be due to differences in ethnicity, geographic distribution, dietary habits, and/or lifestyle modifications.

In the current study, a significant association was detected between hypertension, dyslipidemia, and cardiovascular diseases and the development of CTS. High percentages of patients with CTS had one or more of these diseases. These findings might be explained by the reported high rates of CTS among the studied population. In accordance with this, Alotaibi et al. reported higher incidence $(36.4 \%)$ of hypertension in CTS patients compared to control group [16]. In addition, Sharief et al. demonstrated hypertension in $25 \%$ and dyslipidemia $24 \%$ of patients who were diagnosed with CTS [17]. Küçükakkas and Yurdakul demonstrated that among patients with CTS, 14\% had hypertension [18].

The present study has some limitations. First, this was a public hospital-based study conducted on patients of specific socioeconomic status having a different clinical and risk factor profile, so these results cannot be applied to the general population. Second, the number of cases is small, thus the need of more studies with larger samples is needed to confirm and improve precision of the results.

\section{Conclusion}

Despite the small number of included patients with CTS, the results of the present study suggest that CTS appears to be more severe in patients with MS than patients with obesity. Central obesity is one of the well-known risk factors for CTS, but components of MS may have a greater effect on the severity of CTS. However, further research with larger samples is needed to enforce these results.

\section{References}

1. LeBlanc KE, Cestia W. Carpal tunnel syndrome. Am Fam Physician. 2011;83(8):952-8.

2. Foroozanfar Z, Ebrahimi $\mathrm{H}$, Khanjani $\mathrm{N}$, Bahrampour A Najafipour $H$. Prevalence of carpal tunnel syndrome in diabetic patients with and without metabolic syndrome. J Endocrinol Diabetes Mellit. 2006;4:10-6. https://doi. 
org/10.12970/2310-9971.2016.04.01.2

3. Önder B, Yalçum E, Selçuk B, Kurtaran A, Akyüz M. Carpal tunnel syndrome and metabolic syndrome co-occurrence. Rheumatol Int. 2013;33(3):583-6. https://doi.org/10.1007/ s00296-012-2417-1

PMid:22476246

4. Ricco M, Cattani S, Sigmorelli C. Personal risk factors for carpal tunnel syndrome in female visual display unit workers. Int J Occup Med Environ Health. 2016;29(6):927-36. https://doi. org/10.13075/ijomeh.1896.00781

PMid:27869243

5. Alberti G. Introduction to the metabolic syndrome. Eur Heart J. 2005;7(1):D3-5. https://doi.org/10.1093/eurheartj/sui021

6. Nuttall FQ. Body mass index: Obesity, BMI, and health: A critical review. Nutr Today. 2015;50(3):117-28

PMid:27340299

7. Padua L, LoMonaco M, Gregori B, Valente EM, Padua R, Tonali P. Neurophysiological classification and sensitivity in 500 carpal tunnel syndrome hands. Acta Neurol Scand. 1997;96(4):211-7. https://doi.org/10.1111/j.1600-0404.1997.tb00271.x PMid:9325471

8. Mansoor S, Siddiqui M, Mateen F, Saadat S, Khan ZH, Zahid M, et al. Prevalence of obesity in carpal tunnel syndrome patients: A cross-sectional survey. Cureus. 2017;9(7):e1519. https://doi. org/10.7759/cureus. 1519

PMid:28959514

9. Yurdakul FG, Bodur H, Cakmak OO, Ates C, Sivas F, Eser F, et al. On the severity of carpal tunnel syndrome: Diabetes or metabolic syndrome. J Clin Neurol. 2015;11(3):234-40. https:// doi.org/10.3988/jen.2015.11.3.234

PMid:26174786

10. Balci K, Utku U. Carpal tunnel syndrome and metabolic syndrome. Acta Neurol Scand. 2007;116(2):113-7. https://doi. org/10.1111/j.1600-0404.2007.00797.x PMid: 17661797

11. Reddy $P$, Lent-Schochet $D$, Ramakrishnan $N$, McLaughlin $M$, Jialal I. Metabolic syndrome is an inflammatory disorder:
A conspiracy between adipose tissue and phagocytes. Clin Chim Acta. 2019;496:35-44. https://doi.org/10.1016/j. cca.2019.06.019

PMid:31229566

12. Werner RA, Albers JW, Franzblau A, Armstrong TJ. The relationship between body mass index and the diagnosis of carpal tunnel syndrome. Muscle Nerve. 1994;17(6):632-6. https://doi.org/10.1002/mus.880170610

PMid:8196706

13. Nordstrom DL, Vierkant RA, DeStefano F, Layde PM. Risk factors for carpal tunnel syndrome in a general population. Occupat Environ Med. 1997;54(10):734-40. https://doi. org/10.1136/oem.54.10.734 PMid:9404321

14. Kouyoumdjian JA, Morita MD, Rocha PR, Miranda RC Gouveia GM. Body mass index and carpal tunnel syndrome. Arq Neuropsiquiatr. 2000;58(2A):252-6. https://doi.org/10.1590/ s0004-282x2000000200008 PMid:10849623

15. El Gharieb HA, El Aleem El Gendy A, Rashad MH, Al Bazza OM Serum lipid profile in middle aged female patients with carpal tunnel syndrome. Al-Azhar Med J. 2020;49(1):219-28.

16. Alotaibi SN, Alqahtani SS, Alammar RM, Alqahtani MS, Alshehri SA, Alshehri SF, et al. The prevalence and patterns of carpal tunnel syndrome and their associated risk factors among diabetic population in South-West of Kingdom of Saudi Arabia. Egypt J Hosp Med. 2018;70(7):1152-8. https://doi. org $/ 10.12816 / 0044542$

17. Sharief F, Kanmani J, Kumar S. Risk factors, symptom severity and functional status among patients with carpal tunnel syndrome. Neurol India. 2018;66(3):743-6. https://doi. org/10.4103/0028-3886.232351

PMid:29766936

18. Küçükakkas $O$, Yurdakul OV. The diagnostic value of clinical examinations when diagnosing carpal tunnel syndrome assisted by nerve conduction studies. J Clin Neurosci. 2019;61:136-41. https://doi.org/10.1016/j.jocn.2018.10.106

PMid:30396816 